\title{
Liquid-phase electrical discharge plasmas with a silver electrode for inactivation of a pure culture of Escherichia coli in water
}

Tomislava Vukusic ${ }^{1,4}$, Mengli Shi ${ }^{2,4}$, Zoran Herceg ${ }^{1}$, Shane Rogers ${ }^{3}$, Pooya Esifaee ${ }^{4}$ and Selma Mededovic Thagard ${ }^{4 *}$

${ }^{1}$ Faculty of Food Technology and Biotechnology, Pierottijeva 6, 10000 Zagreb, Croatia

${ }^{2}$ Johns Hopkins University, Whiting School of Engineering, 3400 North Charles Street, Baltimore, MD 21218, USA

${ }^{3}$ Department of Environmental Engineering, Clarkson University, 8 Clarkson Avenue, Potsdam, New York 13699, USA

${ }^{4}$ Plasma Research Laboratory, Department of Chemical and Biomolecular Engineering, Clarkson University, 8 Clarkson Avenue, Potsdam, New York 13699, USA

* Corresponding author. Address: Department of Chemical and Biomolecular Engineering, Clarkson University, 8 Clarkson Avenue, Potsdam, NY 13699, USA. Tel.: +1 315268 4423; fax: +1 3152686654. e-mail address: smededov@clarkson.edu 


\begin{abstract}
This study investigates the possible application of direct-in-liquid electrical discharge plasmas for inactivation of Escherichia coli in water. Aqueous suspensions of pure cultures of Escherichia coli (ATCC 700891) were treated in a reactor that featured point-to-plate electrode configuration. The effects of the high voltage electrode material, plasma discharge frequency, and electrode polarity on inactivation rates were investigated. While it has been observed that all three selected parameters influence the effectiveness of the treatment, the choice of the high voltage electrode material appears to play the most important role. Silver is the most effective electrode material resulting in $6.5 \mathrm{log}$ reduction in $60 \mathrm{~s}$. To develop an understanding of the mechanistic action of silver on Escherichia coli and allow the further development of this technology for water disinfection purposes, control experiments with nanoparticle and ionic silver with and without plasma were performed.
\end{abstract}

Key words: disinfection, electroporation, Escherichia coli, plasma, silver, water 


\section{Introduction}

Harmful microbes are a major threat to human health and the environment. Even today, despite advances in the development of sanitation methods, waterborne disease outbreaks continue to occur (Hilborn et al., 2013; Hlavsa et al., 2014). Chlorination and ultraviolet (UV) radiation are the most commonly used disinfection processes. Although low-cost, chlorination is potentially unsafe because of chemical byproduct formation. UV radiation may be constrained by water transmittance, and is energy intensive (Davis \& Tchobanoglous; Sommer, Cabaj, Pribil, \& Haider, 1997). Other alternatives include ozone, advanced oxidation processes including electrical plasma, and pulsed electric field. Although many are still in the exploratory or developmental stages, these techniques seem to have the potential to ensure the safety and quality of water (Martínez-Huitle \& Brillas, 2008; Moreau, Orange, \& Feuilloley, 2008; Son et al., 2014; Zhang, Wang, Wu, Guan, \& Jia, 2006).

Plasmas formed by direct-in-liquid electrical discharges have been shown to inactivate aqueous suspensions of Escherichia coli, Staphylococcus aureus, Salmonella enterica, Microcystis aeruginosa, Pseudomonas putida, Bacillus subtilis, and others without a significant increase in temperature during the treatment (Abou-Ghazala, Katsuki, Schoenbach, Dobbs, \& Moreira, 2002; Locke, Sato, Sunka, Hoffmann, \& Chang, 2006; Parvulescu, Magureanu, \& Lukes, 2012). Inactivation mechanisms of liquid plasmas have been broadly attributed to chemical (hydrogen peroxide and oxidative radical species such as $\mathrm{OH}$ and $\mathrm{O}$ ), physical (shockwaves and UV), and electrical effects. The relative importance of these individual contributions to the overall inactivation effect will depend on a number of parameters including input energy, duration of the plasma pulse, electrode polarity and material, electrical conductivity, and ionic composition of water (Edebo, Holme, \& Selin, 1969; L. Zhu, He, Gao, Tan, Yue, \& Chang, 2014; Zhu, Zhang, 
Jia, \& Yang, 2009). Before the technology can be optimized and scaled-up, it is important to determine the parameters that influence the treatment process.

This study investigates the effectiveness of direct-in-liquid electrical discharge plasma process for inactivation of Escherichia coli in water as a function of high voltage electrode material, discharge frequency, and electrode polarity. The novelty of the study lies in using silver, a wellknown antimicrobial agent, as the high voltage electrode material, and investigating its mechanistic role in the inactivation process. Escherichia coli was chosen as a model microorganism for two reasons. Firstly, Escherichia coli is one of the most studied pathogenic bacteria. Secondly, while most strains of the bacterium Escherichia coli are harmless and live in the intestines of healthy humans and animals, some of them like E. coli $\mathrm{O} 157: \mathrm{H} 7$ and other enterohaemorrhagic strains of Escherichia coli are still an emerging cause of waterborne illness (World Health Organization, 2004).

\section{Materials and Methods}

\subsection{Experimental Setup}

Experiments were conducted in a $300 \mathrm{~mL}$ glass vessel using a point-to-plane electrode arrangement. Both the high voltage (HV) electrode (nickel-chromium $(\mathrm{NiCr})$ wire, $\mathrm{d}=0.80 \mathrm{~mm}$ or silver $(\mathrm{Ag}$ ) wire, $\mathrm{d}=1.0 \mathrm{~mm}$ ) and the grounded electrode (stainless steel plate, $\mathrm{d}=4.75 \mathrm{~cm}$ ) were immersed in water and separated by a distance of $0.5 \mathrm{~cm}$ (for negative polarity) and $2.0 \mathrm{~cm}$ (for positive polarity), as shown in Fig. 1. Because negative polarity discharges generally require higher voltages to be produced than positive polarity discharges, the strength of the electric field for the negative polarity discharge was increased by decreasing the electrode gap distance (the electric field strength is inversely proportional to the electrode gap distance and directly proportional to the applied voltage). The applied voltage for both positive and negative polarity 
discharge was the same. Electrical discharges were created by charging a load capacitor to $17 \mathrm{kV}$ with a high voltage DC power supply and then discharging the stored charge into the plasma reactor via a rotating spark gap. The frequency of the discharge is determined by the rotation speed of the spark gap, and was varied between $95 \mathrm{~Hz}$ and $250 \mathrm{~Hz}$, depending on the experiment. The electrical circuit diagram is shown in Fig. 2. The voltage and current in the plasma reactor were measured and recorded using a Tektronix P6015A high voltage probe and a Tektronix P6021 current probe connected to a Tektronix TDS 3032C oscilloscope. Unless stated otherwise, all the experiments were performed with positive polarity discharges. Examples of the voltage and current waveforms for both positive and negative discharges are shown in Fig. 3.

Optical emission spectroscopy (OES) measurements were performed by placing an optical fiber connected to an Avaspec Multichannel Fiber Optic Emission Spectrometer (Avantes, AvaSpecULS2048) outside of the reactor perpendicular to the plasma (Fig. 1). The data were collected and analyzed using Avasoft 7.6 software (Avantes) with an integration time of $1600 \mathrm{~ms}$. 


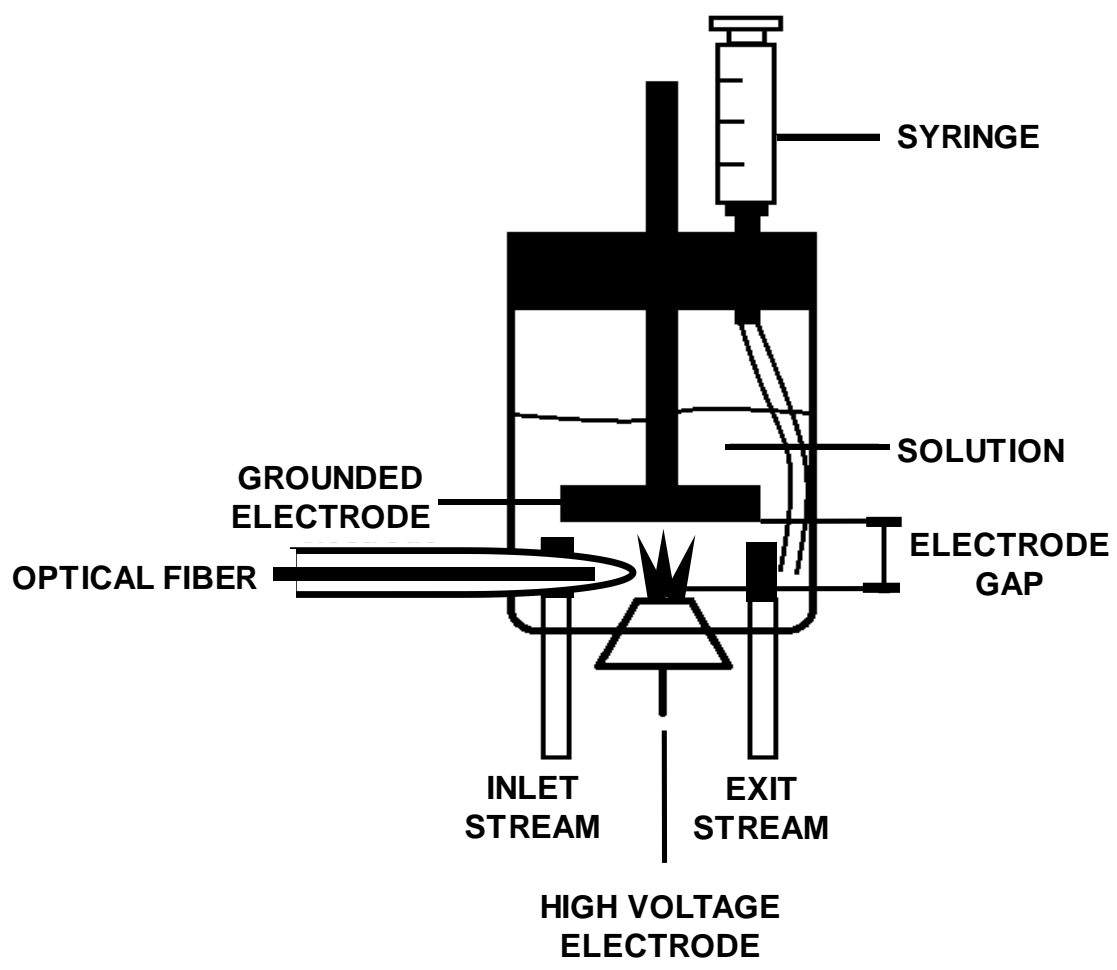

Figure 1. Schematic diagram of the plasma reactor.

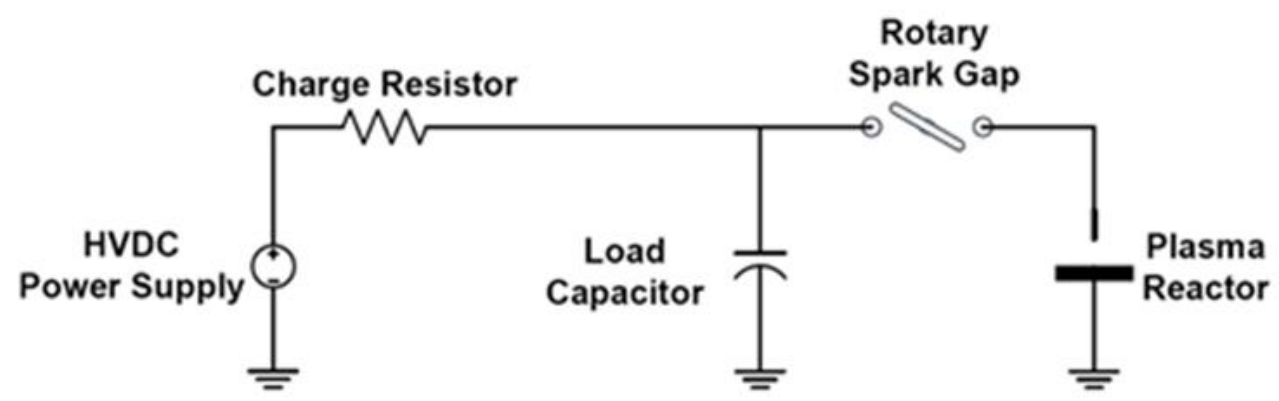

Figure 2. Electrical circuit diagram. 

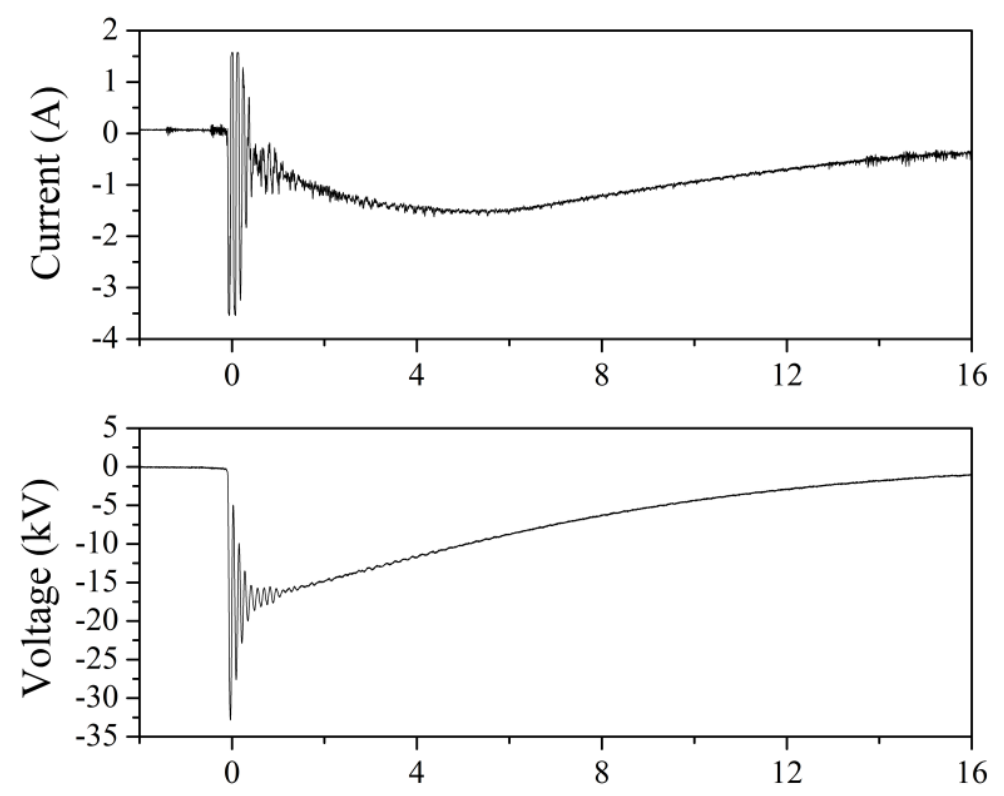

Time $(\mu s)$

(a)
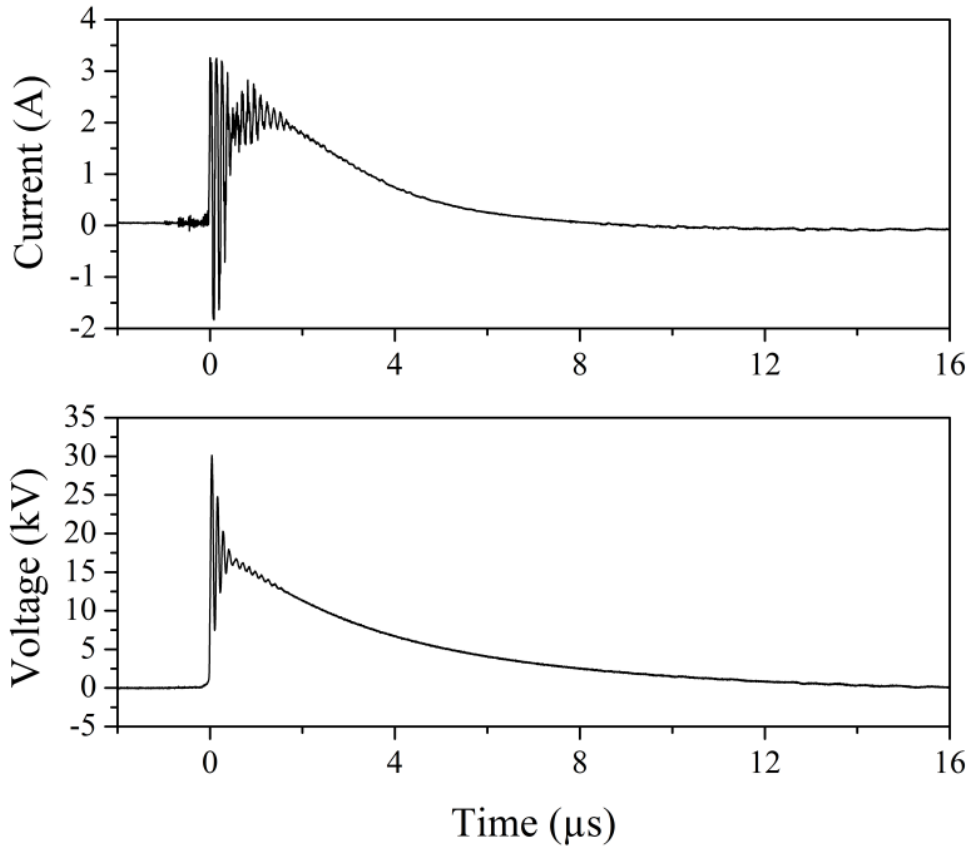

(b)

Figure 3. Voltage and current waveforms for: (a) negative and (b) positive polarity discharges. 


\subsection{Bacteria Preparation and Plating}

Escherichia coli (ATCC 700891) was purchased from the American Type Culture Collection (ATCC, Manassas, VA, USA). Stock cultures of microorganisms were stored in a nutrient broth (Becton, Dickinson and Company (BD), Franklin Lakes, New Jersey, USA) at $4^{\circ} \mathrm{C}$. Before each experiment, bacteria were inoculated into $10 \mathrm{ml}$ tubes containing sterilized Luria-Bertani Miller (LB) broth (BD, USA) and grown by incubation overnight at $37^{\circ} \mathrm{C}$. After the cultivation, the bacterial cells were harvested by centrifugation (Beckman Coulter, Indianapolis IN, USA) at $2400 \mathrm{~g}$ for $10 \mathrm{~min}$ at room temperature. The cell pellet was washed thrice and re-suspended in a sterilized $0.01 \mathrm{M} \mathrm{NaCl}$ solution. Bacterial quantification was completed by standard plate counting (SP) method. Twenty microliter aliquots of 10 -fold serial dilutions were plated on LB agar in triplicate and incubated for $24 \mathrm{~h}$ at $37^{\circ} \mathrm{C}$ prior to counting. Plates with $30-300$ colonies were counted and bacterial population were reported as log colony forming units per $\mathrm{mL}$ (log $\mathrm{CFU} / \mathrm{mL})$.

\subsection{Experimental Methods}

Aqueous suspensions of bacteria were prepared by adding $10 \mathrm{~mL}$ of $0.01 \mathrm{M} \mathrm{NaNO}_{3}$ and $10 \mathrm{~mL}$ of re-suspended bacterial cells in $200 \mathrm{~mL}$ of deionized water. The initial solution conductivity was $100 \mu \mathrm{S} / \mathrm{cm}$.

Experiments were conducted in a semi-batch mode using a peristaltic pump at $1000 \mathrm{~mL} / \mathrm{min}$ to ensure complete mixing of the solution. Unless stated differently, aqueous samples were withdrawn from the reactor every $30 \mathrm{~s}$ and analyzed immediately using the SP technique described in Section 2.2. The initial temperature of the solution in the reactor was $22^{\circ} \mathrm{C}$. For all experiments, the solution temperature after the treatment was between 23 and $26^{\circ} \mathrm{C}$. Conductivity 
and $\mathrm{pH}$ were measured after each experiment using a portable $\mathrm{pH} /$ conductivity meter (Orion 4 star, Thermo Scientific). The concentration of silver ions $\left(\mathrm{Ag}^{+}\right)$in the solution was determined by the flow injection analysis technique (Özel, Liu, Alkasir, \& Andreescu, 2014). All experiments were run in triplicate and reported values represent the mean value of three different experiments. Statistical analyses were performed with SigmaPlot 12.3 (Systat Software GmbH, Erkrath, Germany). Two sample t-test with a significance level of 0.05 was applied.

\subsection{Scanning Electron Microscopy}

The plasma-treated aqueous solution was centrifuged and supernatant discarded in order to obtain dense cell pellets for scanning electron microscopy (SEM). The SEM sample preparation followed the protocol described by (Ziuzina, Patil, Cullen, Keener, \& Bourke, 2013). Cell pellets were fixed for $2 \mathrm{~h}$ by $2.5 \%$ glutaraldehyde in sodium cacodylate buffer (SCB) in an ice bath, then washed three times with SCB followed by fixation in $1 \%$ osmium tetroxide at $4^{\circ} \mathrm{C}$ for $2 \mathrm{~h}$. The fixed cells were washed three times with SCB, and then three times with deionized water. Dehydration of samples was achieved by washing with increasing concentrations of ethyl alcohol (50, 70, 80, 90, 99.5\%, Sigma Aldrich, 200 proof, molecular biology grade). In last step, all samples were freeze-dried (Dura Stop/Dura Dry Freeze Dryer, model\#TDS2C0B50B0), then fixed on carbon tape and sputter-coated with gold particles for 2 min. Images were taken by JEOL (JSM-7400F, Field Emission Electron Microscopy, US) at $1 \mathrm{kV}$.

\section{Results}

\subsection{Electrode Material}

Fig. 4 compares inactivation of Escherichia coli in an aqueous suspension using nickel-chromium and silver high voltage electrodes. Liquid plasma discharge using a silver HV electrode resulted 
in $\sim 6.5 \log$ reduction in $60 \mathrm{~s}$ compared to $<1 \log$ reduction using a $\mathrm{NiCr}$ electrode for the same treatment time. The effect of the HV electrode material on inactivation of Escherichia coli was statistically significant $(\mathrm{P}=<0.001)$.

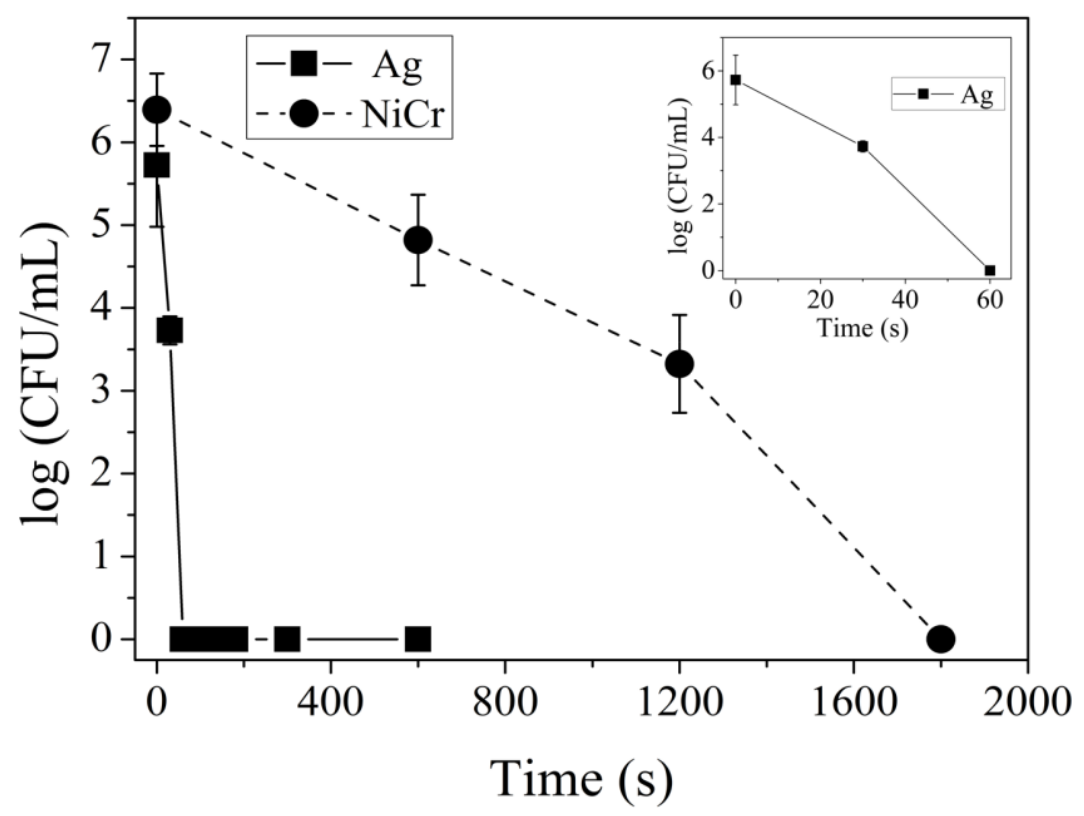

Figure 4. The effect of the HV electrode material on inactivation of Escherichia coli at $120 \mathrm{~Hz}$ discharge frequency. Insert: early treatment times showing the effect of Ag HV electrode.

\subsection{Discharge Frequency and Electrode Polarity}

Table 1 reports the time required for $5 \log$ reduction of Escherichia coli suspensions at different discharge frequencies using silver as the HV anode. In the frequency range investigated, there is an optimum discharge frequency for the Escherichia coli inactivation of $120 \mathrm{~Hz}$. Discharge power, also reported in Table 1, was calculated from Equation 1:

$$
P=\frac{1}{2} \times C \times V^{2} \times f
$$


where $C(=0.75 \mathrm{nF})$ is the capacitance of the load capacitor, $V(=17 \mathrm{kV})$ is the applied voltage, and $f(\mathrm{~Hz})$ is the discharge frequency. Because $P$ is directly proportional to $f$, discharge power increases with an increase in frequency. However, according to the results, there is no obvious correlation between the discharge power and the inactivation time.

Table 1. The effect of the discharge frequency on inactivation of Escherichia coli. The high voltage electrode is a silver anode $(+)$.

\begin{tabular}{lll}
\hline $\begin{array}{l}\text { Frequency } \\
(\mathrm{Hz})\end{array}$ & $\begin{array}{l}\text { Power } \\
(\mathrm{W})\end{array}$ & $\begin{array}{l}\text { Time for } 5 \mathrm{log} \\
\text { reduction }(\mathrm{s})\end{array}$ \\
\hline 95 & 21.1 & 300 \\
105 & 23.4 & 120 \\
120 & 26.7 & 60 \\
140 & 31.1 & 90 \\
170 & 37.8 & $<5 \log ^{*}$ \\
250 & 55.6 & $<5 \log ^{*}$ \\
\hline * 5 log reduction achieved in $300 \mathrm{~s}$
\end{tabular}

Plasma discharge polarity had a significant effect $(\mathrm{P}=<0.001)$ on bacterial decimation rates, as shown in Fig. 5. For negative polarity plasmas at $120 \mathrm{~Hz}, 5 \log$ reduction was achieved within 30 $\mathrm{s}$, compared to $60 \mathrm{~s}$ with a positive polarity discharge at the identical frequency. 


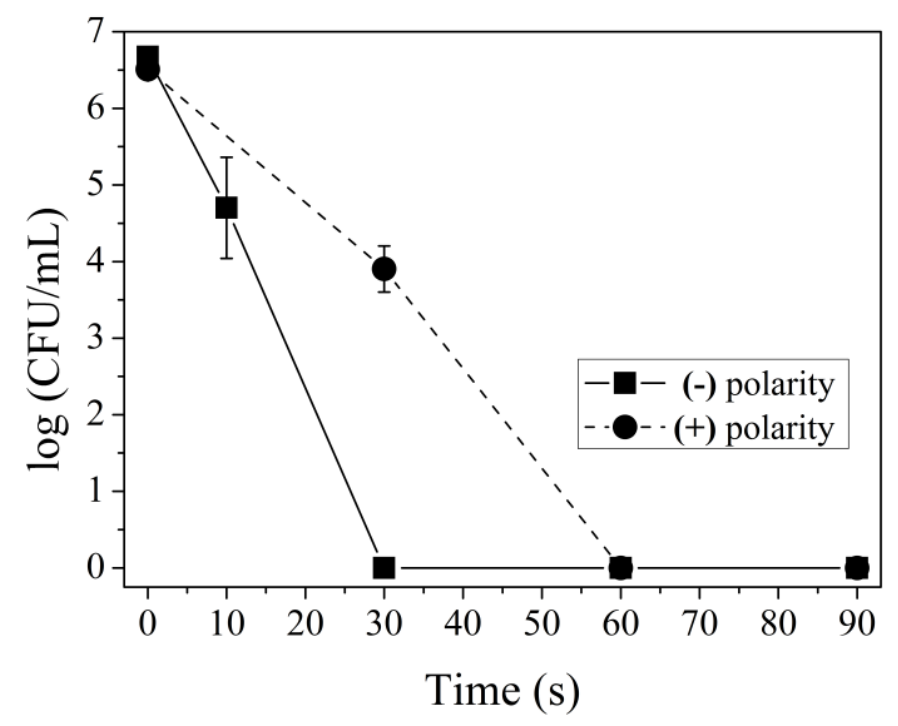

Figure 5. The effect of plasma polarity on inactivation of Escherichia coli (HV electrode material is silver).

\subsection{Mechanistic action of silver on Escherichia coli: effect of nanoparticle and ionic silver}

Due to the effectiveness of the silver electrode during the discharge, experiments were conducted to elucidate the mechanism(s) by which bacterial inactivation rates were increased relative to the NiCr electrode material.

Erosion of the high voltage electrode during a direct-in-liquid electrical discharge has been shown to release both ions and metal particles in the bulk solution (Potocký, Saito, \& Takai, 2009). The phenomenon is believed to result from a series of events initiated by current heating leading to electrode material melting (Goryachev, Ufimtsev, \& Khodakovskii, 1997; Holzer \& Locke, 2008; Lukeš, et al., 2006). In this study, the release of silver particles from the electrode was confirmed qualitatively by collecting and filtering the plasma-treated solution with a $0.5 \mu \mathrm{m}$ filter and observing a layer of metallic silver deposited on the filter. The presence of silver in the plasma was confirmed by optical emission spectroscopy (Fig. 6). It must be noted that the 242 
and $328 \mathrm{~nm}$ silver lines originate from excited silver particles that were either sputtered from the HV electrode or formed by the reduction of the silver ions released from the electrode. The concentration profile of $\mathrm{Ag}^{+}$in the bulk liquid released by the silver electrode for positive and negative polarity plasmas is shown in Fig. 7.

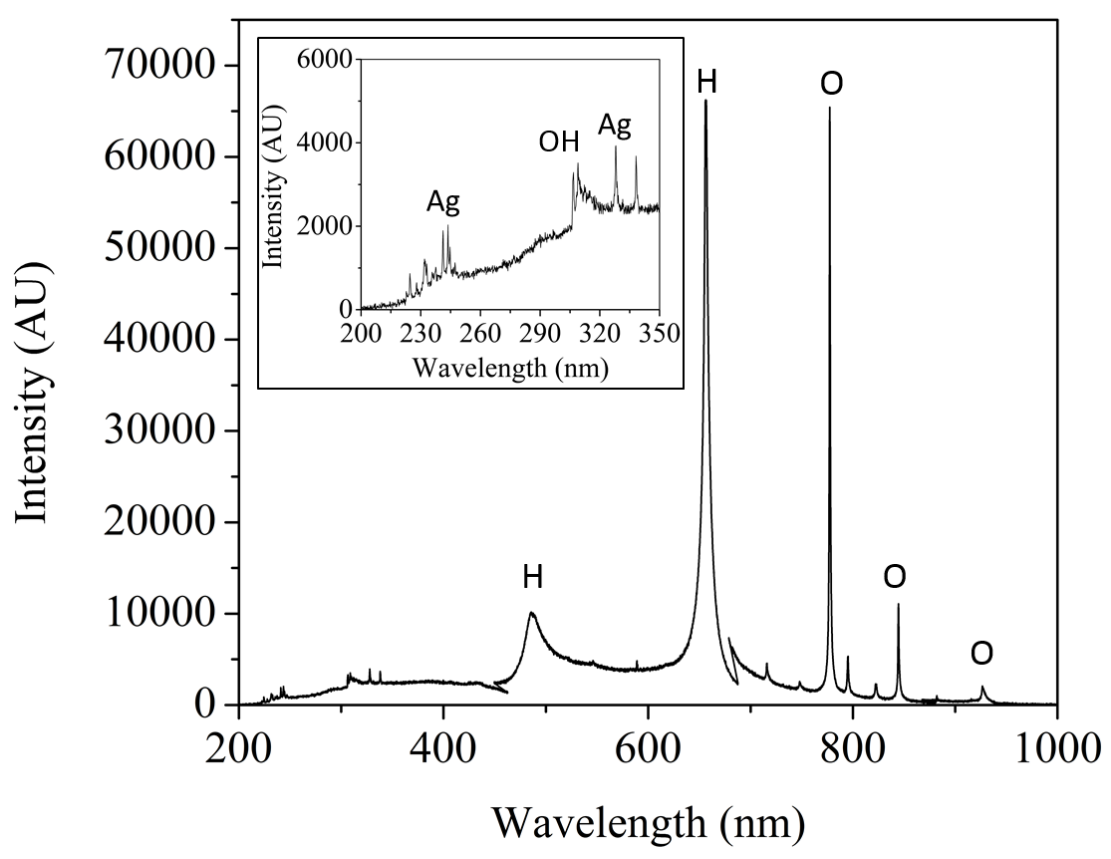

Figure 6. Optical emission spectrum of plasma recorded with the silver high voltage electrode. Insert: wavelengths showing emissions from excited Ag. 


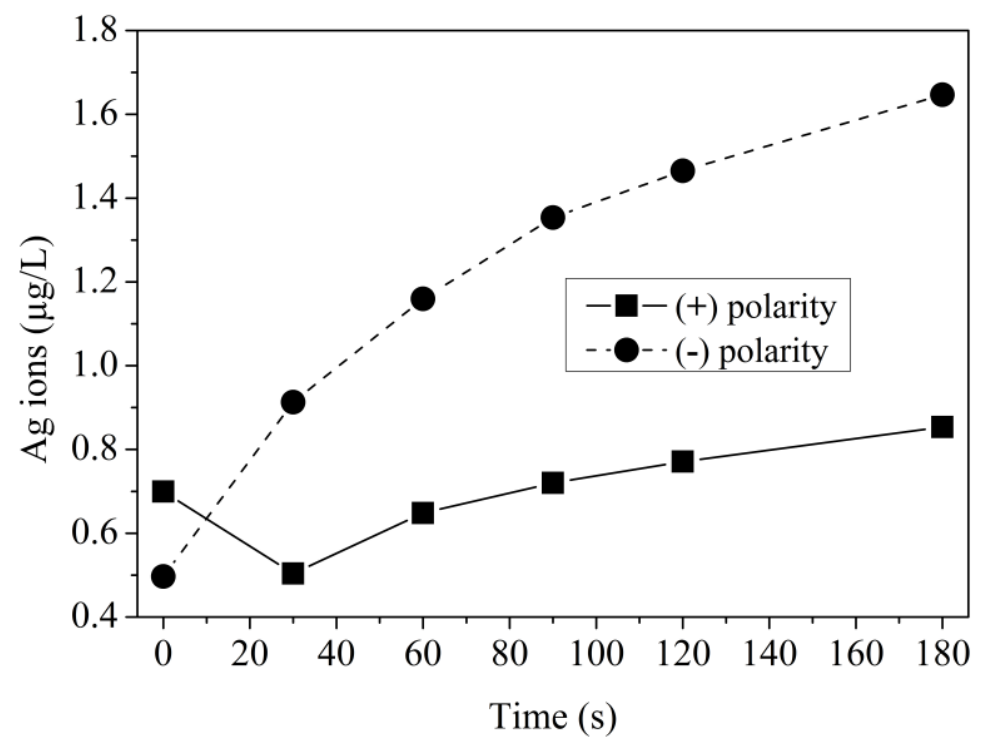

Figure 7. Concentration of $\mathrm{Ag}^{+}$in the bulk liquid produced during the treatment at different electrode polarities at the frequency of $120 \mathrm{~Hz}$.

Both silver nanoparticles (AgNPs) and silver ions $\left(\mathrm{Ag}^{+}\right)$have well-known antibacterial and antiviral properties against a wide range of microorganisms including Escherichia coli (Morones, et al., 2005; Sondi \& Salopek-Sondi, 2004). To investigate effect of released silver on inactivation of Escherichia coli, experiments with AgNPs and solution of $\mathrm{AgNO}_{3}$ salt in the absence and presence of plasma were performed.

Commercial AgNPs $\left(500 \mathrm{mg} / \mathrm{L}\right.$, size $<100 \mathrm{~nm}$, surface area $5.0 \mathrm{~m}^{2} / \mathrm{g}, 99.5 \%$ trace metals basis $)$ were added to two separate solutions containing Escherichia coli (the differences among the initial concentrations shown in Fig. 8 are due to an experimental error). The $500 \mathrm{mg} / \mathrm{L}$ concentration of AgNPs was chosen arbitrarily since the concentration of the metallic silver released from the HV electrode has not been measured. One solution was exposed to in-liquid plasma discharge using $\mathrm{NiCr}$ electrode for up to five minutes. The other solution containing the same concentration of AgNPs was incubated for five minutes without the plasma (Fig. 8). 
Despite the known toxicity of AgNPs to bacteria (AshaRani, Low Kah Mun, Hande, \& Valiyaveettil, 2008; Kim et al., 2007), the inactivation rate was low compared to that in the presence of the plasma. Since the arbitrarily chosen concentration of AgNPs for this experiment of $500 \mathrm{mg} / \mathrm{L}$ is extremely high and in fact much higher than the measured bulk liquid concentration of the metal eroding from the HV plasma electrode (Kirkpatrick, 2004), another experiment with only $10 \mathrm{mg} / \mathrm{L}$ of AgNP was performed. As shown in Fig.8, this concentration of silver is not high enough to cause significant inactivation.

To explore potential $\mathrm{Ag}^{+}$ion toxicity effects, Escherichia coli was further exposed to 2 and 20 $\mu \mathrm{g} / \mathrm{L}$ solutions of $\mathrm{AgNO}_{3}$ salt (Fig. 9). Selected concentrations for $\mathrm{AgNO}_{3}$ are based on the concentration of the silver ions produced by the plasma treatment $(\sim 2 \mu \mathrm{g} / \mathrm{L}$, positive polarity, Fig. 7) and published papers (20 $\mu \mathrm{g} / \mathrm{L})$ (Feng, Wu, Chen, Cui, Kim, \& Kim, 2000; Sondi et al., 2004). The treatment effects were comparable to those of AgNPs in the absence of the plasma and therefore could not explain the overall treatment effect observed when Escherichia coli was exposed to in-liquid plasmas using a silver electrode. Indeed, Fig.10 shows that the presence of either of the two concentrations of $\mathrm{Ag}^{+}$ions in the solution has a negligible effect on the treatment effectiveness when $\mathrm{NiCr}$ is used as the $\mathrm{HV}$ electrode material. Almost identical inactivation curve is reported in Fig. 4 for the plasma treatment of bacterial suspension containing only $\mathrm{NaNO}_{3}$. Control (no plasma) experiments conducted with $12 \mathrm{mg} / \mathrm{L}$ and higher concentrations of $\mathrm{Ag}^{+}$revealed significant inactivation even at $\mathrm{t}=0$ min (data not shown). 


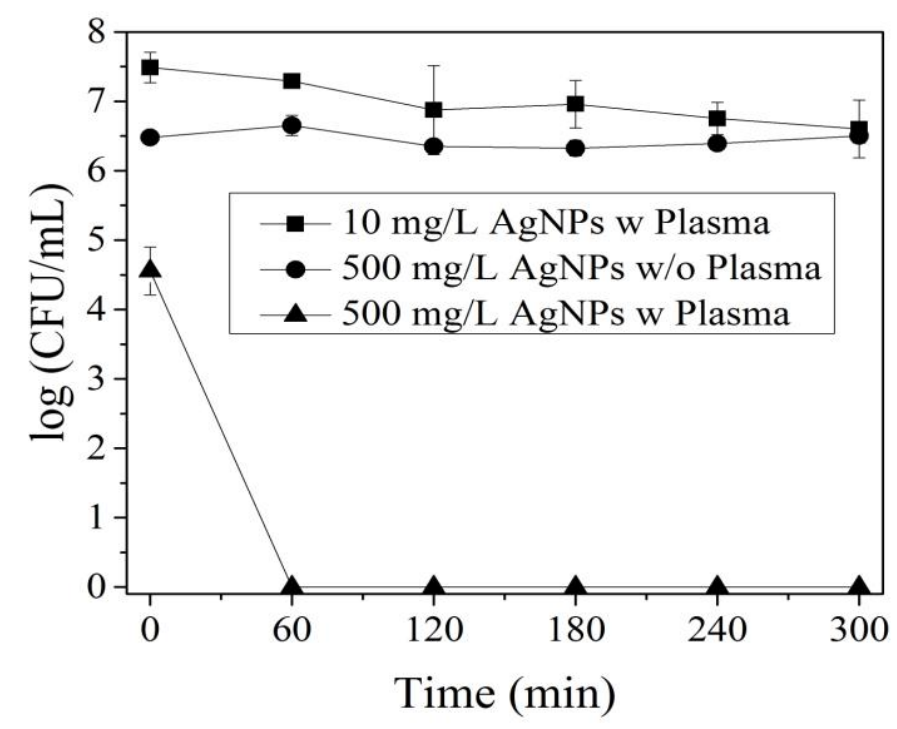

Figure 8. The comparison of inactivation effect of two different concentrations of AgNPs with (HV electrode material is $\mathrm{NiCr}$, positive polarity, $120 \mathrm{~Hz}$ ) and without electrical discharge plasma.

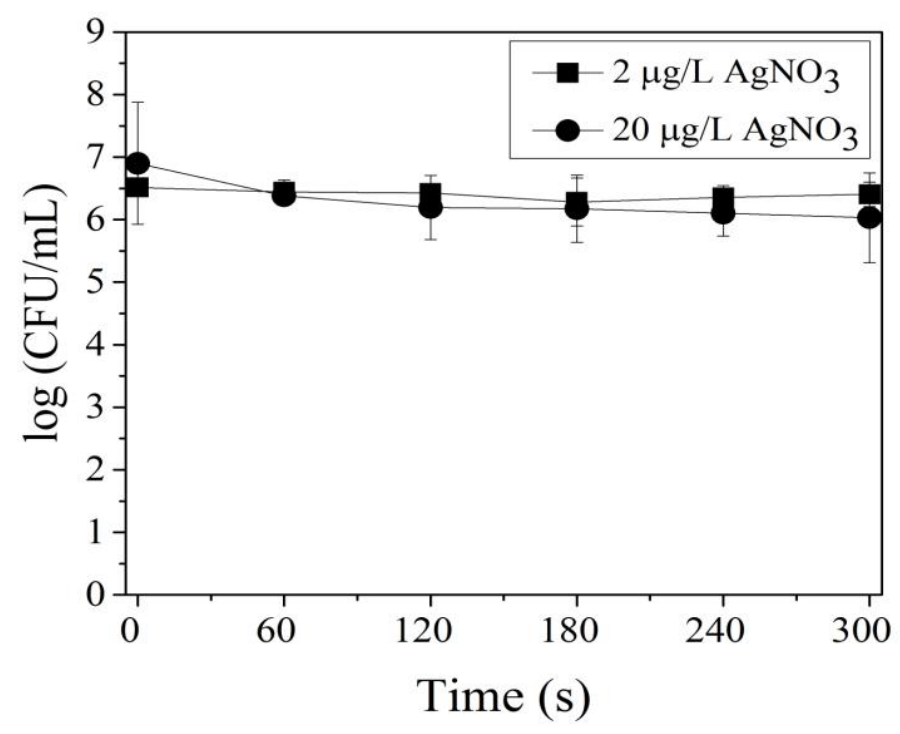

Figure 9. Control experiments with the addition of $\mathrm{AgNO}_{3}$ salt. Electrical discharge plasma is turned off. The solution conductivity is $100 \mu \mathrm{S} / \mathrm{cm}$. 


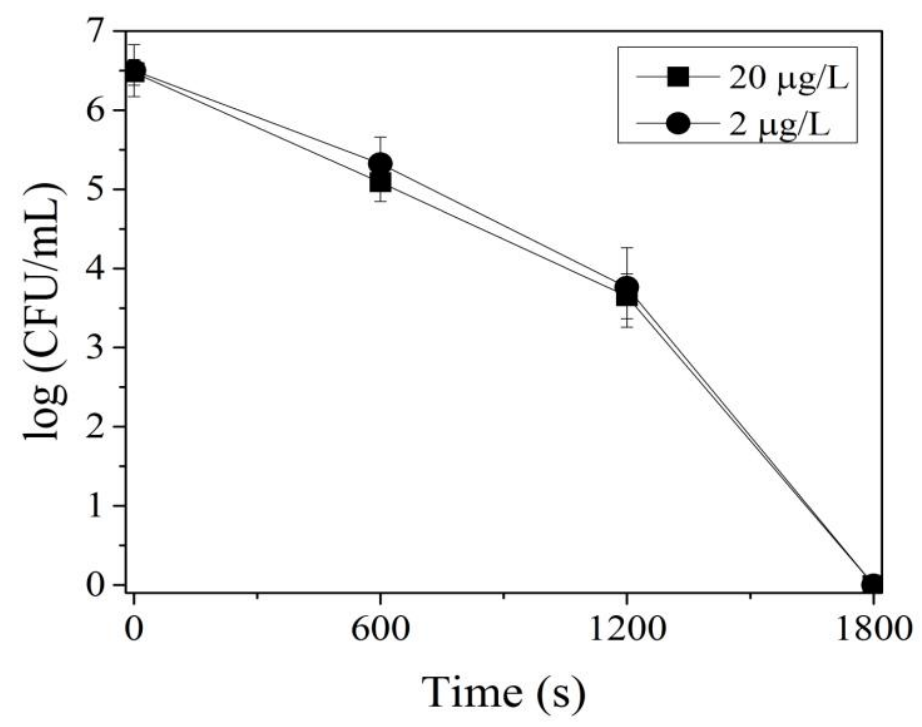

Figure 10. Plasma treatment of Escherichia coli in the presence of 2 and $20 \mu \mathrm{g} / \mathrm{L} \mathrm{AgNO}$. $\mathrm{HV}$ electrode is $\mathrm{NiCr}$ (positive polarity). The discharge frequency is $120 \mathrm{~Hz}$.

SEM analysis was utilized to visualize the effect of the plasma treatment on the morphology of the bacteria. Figure 11 shows SEM images of untreated and plasma-treated Escherichia coli. Prior to the treatment, images confirmed the presence of healthy cells, whereas after the liquid plasma discharge treatment, a large portion of bacterial cells was found to have small holes similar to those observed during electroporation (Liu et al., 2014; Martínez-Huitle et al., 2008; Pliquett, Joshi, Sridhara, \& Schoenbach, 2007). 


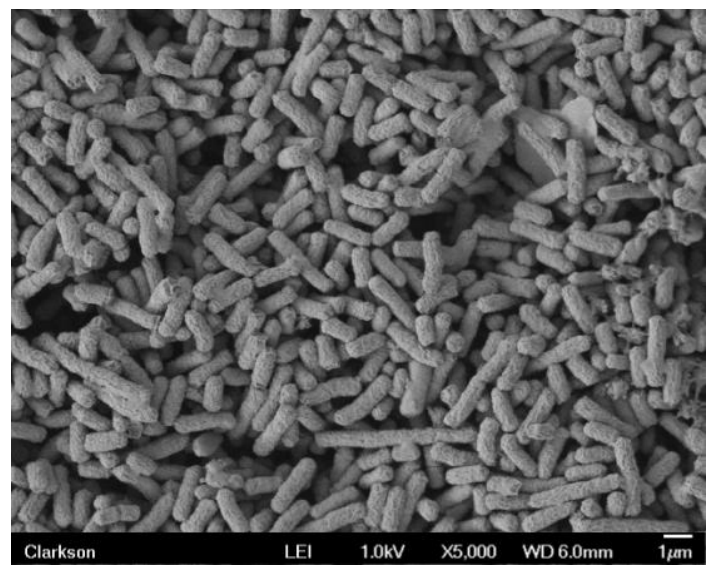

(a)

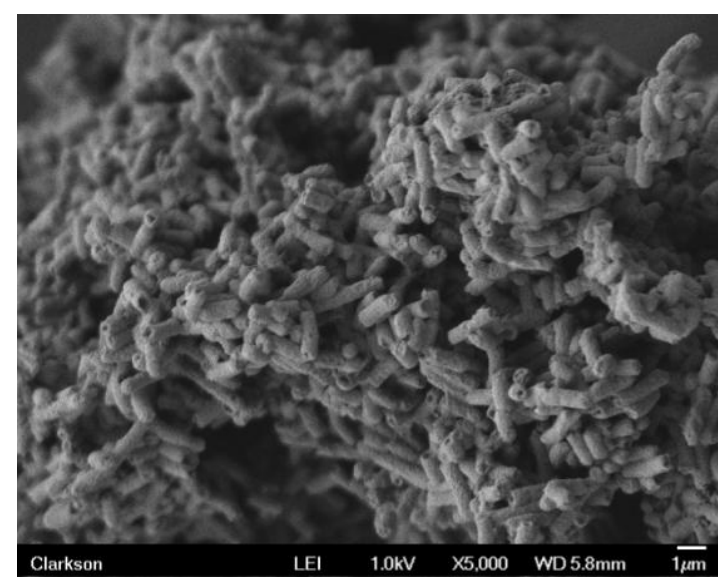

(b)

Figure 11. SEM images of (a) untreated and (b) plasma treated (treatment time is 12 min and the HV electrode is silver) Escherichia coli.

\section{Discussion}

Despite significant efforts to understand the mechanism(s) by which aqueous plasmas inactivate microorganisms, the best of the hypotheses are still limited to the "combined outcome of chemical, physical and electrical effects". Due to the obvious complexity of the subject, the focus of this study was not on elucidating the mechanism of inactivation but in using experimental findings to offer an explanation for the superior performance of the silver compared to the $\mathrm{NiCr}$ HV electrode material. The following inactivation mechanism is thus proposed for plasma discharges in liquid with silver HV electrode, and does not constitute the general mechanism for cases with other conditions or other HV electrode materials.

The Reactive Oxidative Species (ROS) produced directly by the plasma such as $\mathrm{OH}$ and $\mathrm{HO}_{2}$ radicals are expected to play a very limited role in the inactivation of the suspended bacteria due to their short lifetimes and diffusion lengths (Sato, Ohgiyama, \& Clements, 1996). However, even though these species may react with the membrane of cells that are very near to the plasma 
channel, this oxidative inactivation pathway is most likely insignificant due to bulk liquid transport limitations. Also, the intensity of the UV light produced by low power discharges such as those used in this study is too low to have any effect on the inactivation (Lukes, Clupek, Babicky, \& Sunka, 2008). Fundamental mechanistic experiments that were performed in our laboratory as a part of another study confirm these hypotheses and further suggest that at solution electrical conductivities $<200 \mu \mathrm{S} / \mathrm{cm}$ the single most significant inactivation mechanism is the electric field-induced electroporation which was also demonstrated in this study.

Electroporation alone could potentially explain why pulsed electrical discharges in water that use a non-catalytic $\mathrm{HV}$ electrode material such as $\mathrm{NiCr}$ inactivate Escherichia coli. However, the use of silver results in additional effects that lead to significantly higher inactivation rates. The Ag electrode releases both silver ions and silver nanoparticles into the surrounding solution. Control plasma experiments conducted with $\mathrm{Ag}^{+}$at the concentration that is released after a 3-minute plasma treatment suggest that these ions alone cannot explain the effects observed when silver is used as the HV electrode. Notably, control experiments conducted without the plasma with concentrations of $\mathrm{Ag}^{+}$that are $\sim 0.2$ and $\sim 11$ times higher than those released by the silver electrode are consistent with the known antimicrobial properties of silver (Jung, Koo, Kim, Shin, Kim, \& Park, 2008; Pandian, Deepak, Kalishwaralal, Viswanathan, \& Gurunathan, 2010). Although our control experiments suggest that $\mathrm{Ag}^{+}$are not responsible for the superior performance of the silver $\mathrm{HV}$ electrode, literature reports that a continuous release of $\mathrm{Ag}^{+}$ions exhibits higher antimicrobial effects than adding a specific amount of $\mathrm{Ag}^{+}$at the beginning of the experiment (Liau, Read, Pugh, Furr, \& Russell, 1997) and that electrically generated $\mathrm{Ag}^{+}$has better antimicrobial properties than other silver-based compounds (Berger, Spadaro, Bierman, Chapin, \& Becker, 1976; Berger, Spadaro, Chapin, \& Becker, 1976). 
In the absence of the plasma, AgNPs exhibited a negligible effect on the inactivation. However, when the plasma was turned on, the extent of the inactivation strongly depended on the concentration of the commercially added particles, as suggested by literature (Sondi et al., 2004). Due to the inability to measure the concentration of the particles emitted by the silver HV electrode, two extreme concentrations of AgNPs were used: $12 \mathrm{mg} / \mathrm{L}$ and $500 \mathrm{mg} / \mathrm{L}$. Since the concentration of the silver particles released into the bulk liquid during the plasma treatment most likely lies between these two extremes, we believe that AgNPs and not silver ions are responsible for the superior performance of the silver HV electrode. It must also be mentioned that the size of the silver particles emitted by the plasma electrode is most likely significantly smaller than 100 $\mathrm{nm}$ which is the size of the commercial AgNPs used in these experiments. The shape and the size of AgNPs are known to have a significant effect on the inactivation effectiveness (Agnihotri, Mukherji, \& Mukherji, 2014).

The mechanism of deactivation of Escherichia coli by AgNPs is not completely clear although studies suggest that AgNPs increase the permeability of the cell wall by attaching to it, resulting in cell death. Also, the penetration of AgNPs inside the bacteria and their interaction with sulfur and phosphorus compounds such as DNA has been observed (Morones et al., 2005). After AgNPs react with intracellular materials, DNA loses its replication ability and cellular proteins are inactivated. Direct-in-liquid discharge plasma treatment facilitates the penetration of the nanoparticles by electroporating the cell wall which amplifies the bactericidal effect of AgNPs.

In our results, we showed how at certain frequencies during negative discharge using silver HV electrode bacterial cells are inactivated faster than for the positive polarity treatment. Again, the possible pathway of inactivation originates from the assumption that the cell membrane is physically affected by short pulses of electric field, which allows AgNPs (and $\mathrm{Ag}^{+}$ions) to enter 
freely into the cytoplasm of Escherichia coli cells. Because negative polarity discharges had a higher voltage gradient (smaller electrode gap) compared to the positive polarity, this enhanced electroporation featured an observably higher rate of electrode erosion, which increased the presence of $\mathrm{Ag}$ in the solution.

The complicated relationship between discharge frequency and inactivation rate is thought to be due to the pulsed electric field. The amount of time between subsequent pulses (inversely proportional to discharge frequency) influences the number and size distribution of the pores formed via electroporation (Garner et al., 2007; Joshi \& Schoenbach, 2002; Weaver \& Chizmadzhev, 1996), which would in turn affect the amount of Ag ions and AgNPs as well as the size of AgNPs that are able to enter into the cell interior. Though it could not be confirmed that this particular phenomenon accounted for the non-linear nature of the frequency-inactivation rate relationship, it was accepted as the most likely explanation.

\section{Conclusions}

In this study, we have shown that liquid discharge plasma is an effective method for inactivation of Escherichia coli. Liquid discharges with negative polarity achieve much higher inactivation rates than with positive polarity. Discharge frequency plays a complex role in the inactivation, where the inactivation rate decreases at higher frequencies despite the higher input power. Directin-liquid discharge plasma treatment electroporates the cell wall. The superior performance of the silver high voltage electrode compared to $\mathrm{NiCr}$ electrode is due to the penetration of the silver nanoparticles released into the solution from electrode erosion into the cell interior. 


\section{Acknowledgments}

This project was supported by the New York State Pollution Prevention Institute project number 100196 and the National Science Foundation under Grant No. EEC-1359256. The authors thank Dr. Silvana Andreescu in the Department of Chemistry, Clarkson University for providing measurements of the silver ion concentrations and Dr. Richard Partch also in the Department of Chemistry for allowing us to use the Freeze-Dryer. 


\section{References}

Abou-Ghazala, A., Katsuki, S., Schoenbach, K. H., Dobbs, F. C., \& Moreira, K. R. (2002). Bacterial decontamination of water by means of pulsed-corona discharges. Plasma Science, IEEE Transactions on, 30(4), 1449-1453.

Agnihotri, S., Mukherji, S., \& Mukherji, S. (2014). Size-controlled silver nanoparticles synthesized over the range 5-100 $\mathrm{nm}$ using the same protocol and their antibacterial efficacy. RSC Advances, 4(8), 3974-3983.

AshaRani, P., Low Kah Mun, G., Hande, M. P., \& Valiyaveettil, S. (2008). Cytotoxicity and genotoxicity of silver nanoparticles in human cells. ACS nano, 3(2), 279-290.

Berger, T., Spadaro, J., Bierman, R., Chapin, S., \& Becker, R. (1976). Antifungal properties of electrically generated metallic ions. Antimicrobial Agents and Chemotherapy, 10(5), 856860.

Berger, T., Spadaro, J., Chapin, S., \& Becker, R. (1976). Electrically generated silver ions: quantitative effects on bacterial and mammalian cells. Antimicrobial Agents and Chemotherapy, 9(2), 357.

Davis, C., \& Tchobanoglous, G. Evaluation of Disinfection Units for Onsite Wastewater Treatment Systems.

Edebo, L., Holme, T., \& Selin, I. (1969). Influence of the conductivity of the discharge liquid on the microbicidal effect of transient electric arcs in aqueous systems. Applied microbiology, 17(1), 59-62.

Feng, Q., Wu, J., Chen, G., Cui, F., Kim, T., \& Kim, J. (2000). A mechanistic study of the antibacterial effect of silver ions on Escherichia coli and Staphylococcus aureus. Journal of biomedical materials research, 52(4), 662-668. 
Garner, A. L., Chen, G., Chen, N., Sridhara, V., Kolb, J. F., Swanson, R. J., Beebe, S. J., Joshi, R. P., \& Schoenbach, K. H. (2007). Ultrashort electric pulse induced changes in cellular dielectric properties. Biochemical and biophysical research communications, 362(1), 139144.

Goryachev, V., Ufimtsev, A., \& Khodakovskii, A. (1997). Mechanism of electrode erosion in pulsed discharges in water with a pulse energy of 1 J. Technical Physics Letters, 23(5), 386-387.

Hilborn, E. D., Wade, T. J., Hicks, L., Garrison, L., Carpenter, J., Adam, E., Mull, B., Yoder, J., Roberts, V., \& Gargano, J. W. (2013). Surveillance for waterborne disease outbreaks associated with drinking water and other nonrecreational water-United States, 2009-2010. MMWR-Morbidity and Mortality Weekly Report, 62(35), 714-720.

Hlavsa, M. C., Roberts, V. A., Kahler, A. M., Hilborn, E. D., Wade, T. J., Backer, L. C., \& Yoder, J. S. (2014). Recreational water-associated disease outbreaks-United States, 2009-2010. MMWR Morb Mortal Wkly Rep, 63(1), 6-10.

Holzer, F., \& Locke, B. R. (2008). Influence of high voltage needle electrode material on hydrogen peroxide formation and electrode erosion in a hybrid gas-liquid series electrical discharge reactor. Plasma Chemistry and Plasma Processing, 28(1), 1-13.

Joshi, R., \& Schoenbach, K. (2002). Mechanism for membrane electroporation irreversibility under high-intensity, ultrashort electrical pulse conditions. Physical Review E, 66(5), 052901.

Jung, W. K., Koo, H. C., Kim, K. W., Shin, S., Kim, S. H., \& Park, Y. H. (2008). Antibacterial activity and mechanism of action of the silver ion in Staphylococcus aureus and Escherichia coli. Applied and environmental microbiology, 74(7), 2171-2178. 
Kim, J. S., Kuk, E., Yu, K. N., Kim, J.-H., Park, S. J., Lee, H. J., Kim, S. H., Park, Y. K., Park, Y. H., \& Hwang, C.-Y. (2007). Antimicrobial effects of silver nanoparticles. Nanomedicine: Nanotechnology, Biology and Medicine, 3(1), 95-101.

Kirkpatrick, M. J. (2004). Plasma-catalyst interactions in treatment of gas phase contaminants and in electrical discharge in water. College of Engineering, Florida State University, Tallahassee, FL, USA.

Liau, S., Read, D., Pugh, W., Furr, J., \& Russell, A. (1997). Interaction of silver nitrate with readily identifiable groups: relationship to the antibacterialaction of silver ions. Letters in applied microbiology, 25(4), 279-283.

Liu, C., Xie, X., Zhao, W., Yao, J., Kong, D., Boehm, A. B., \& Cui, Y. (2014). Static electricity powered copper oxide nanowire microbicidal electroporation for water disinfection. Nano letters, 14(10), 5603-5608.

Locke, B., Sato, M., Sunka, P., Hoffmann, M., \& Chang, J.-S. (2006). Electrohydraulic discharge and nonthermal plasma for water treatment. Industrial \& engineering chemistry research, 45(3), 882-905.

Lukes, P., Clupek, M., Babicky, V., \& Sunka, P. (2008). Ultraviolet radiation from the pulsed corona discharge in water. Plasma Sources Science and Technology, 17(2), 024012.

Lukeš, P., Člupek, M., Babický, V., Šunka, P., Skalný, J., Štefečka, M., Novak, J., \& Malkova, Z. (2006). Erosion of needle electrodes in pulsed corona discharge in water. Czechoslovak Journal of Physics, 56(2), B916-B924.

Martínez-Huitle, C. A., \& Brillas, E. (2008). Electrochemical alternatives for drinking water disinfection. Angewandte Chemie International Edition, 47(11), 1998-2005.

Moreau, M., Orange, N., \& Feuilloley, M. (2008). Non-thermal plasma technologies: new tools for bio-decontamination. Biotechnology advances, 26(6), 610-617. 
Morones, J. R., Elechiguerra, J. L., Camacho, A., Holt, K., Kouri, J. B., Ramírez, J. T., \& Yacaman, M. J. (2005). The bactericidal effect of silver nanoparticles. Nanotechnology, 16(10), 2346.

Pandian, S. R. K., Deepak, V., Kalishwaralal, K., Viswanathan, P., \& Gurunathan, S. (2010). Mechanism of bactericidal activity of Silver Nitrate-a concentration dependent bifunctional molecule. Brazilian Journal of Microbiology, 41(3), 805-809.

Parvulescu, V. I., Magureanu, M., \& Lukes, P. (2012). Plasma chemistry and catalysis in gases and liquids: John Wiley \& Sons.

Pliquett, U., Joshi, R., Sridhara, V., \& Schoenbach, K. (2007). High electrical field effects on cell membranes. Bioelectrochemistry, 70(2), 275-282.

Potocký, Š., Saito, N., \& Takai, O. (2009). Needle electrode erosion in water plasma discharge. Thin Solid Films, 518(3), 918-923.

Sato, M., Ohgiyama, T., \& Clements, J. S. (1996). Formation of chemical species and their effects on microorganisms using a pulsed high-voltage discharge in water. Industry Applications, IEEE Transactions on, 32(1), 106-112.

Sommer, R., Cabaj, A., Pribil, W., \& Haider, T. (1997). Influence of lamp intensity and water transmittance on the UV disinfection of water. Water science and technology, 35(11), 113-118.

Son, E. E., Suvorov, I. F., Kakurov, S., Gaisin, A. F., Samitova, G. n. T. e., Solov'eva, T. y. L., Yudin, A. S., \& Rakhletsova, T. y. V. (2014). Electrical discharges with liquid electrodes used in water decontamination. High Temperature, 52(4), 490-496.

Sondi, I., \& Salopek-Sondi, B. (2004). Silver nanoparticles as antimicrobial agent: a case study on E. coli as a model for Gram-negative bacteria. Journal of colloid and interface science, 275(1), 177-182. 
Weaver, J. C., \& Chizmadzhev, Y. A. (1996). Theory of electroporation: a review. Bioelectrochemistry and bioenergetics, 41(2), 135-160.

World Health Organization. (2004). Guidelines for drinking-water quality: recommendations (Vol. 1): World Health Organization.

Zhang, R., Wang, L., Wu, Y., Guan, Z., \& Jia, Z. (2006). Bacterial Decontamination of Water by Bipolar Pulsed Discharge in a Gas\&\# 8211; Liquid\&\# 8211; Solid Three-Phase Discharge Reactor. Plasma Science, IEEE Transactions on, 34(4), 1370-1374.

Zhu, L., He, Z.-H., Gao, Z.-W., Tan, F.-L., Yue, X.-G., \& Chang, J.-S. (2014). Research on the influence of conductivity to pulsed arc electrohydraulic discharge in water. Journal of Electrostatics, 72(1), 53-58.

Zhu, T., Zhang, Q., Jia, Z., \& Yang, L. (2009). The effect of conductivity on streamer initiation and propagation between dielectric-coated sphere-plate electrodes in water. Dielectrics and Electrical Insulation, IEEE Transactions on, 16(6), 1552-1557.

Ziuzina, D., Patil, S., Cullen, P., Keener, K., \& Bourke, P. (2013). Atmospheric cold plasma inactivation of Escherichia coli in liquid media inside a sealed package. Journal of applied microbiology, 114(3), 778-787. 